\title{
AS POSSIBILIDADES INTERCULTURAIS DE UM CONCEITO DE POVO PARA ALÉM DO NACIONAL
}

\section{THE INTERCULTURAL POSSIBILITIES OF A PEOPLE'S CONCEPT BEYOND THE NATIONAL}

\section{Gustavo Barbosa de Mesquita Batista ${ }^{1}$}

RESUMO: Os elementos modernos conformadores do conceito de Estado: povo, território e soberania, submetem-se a uma redefinição própria da crise paradigmática observada na pós-modernidade. Tornou-se, por exemplo, insuficiente a definição de povo com base no sujeito nacional e passamos a observar possibilidades interculturais para o estabelecimento de um novo conceito de povo. O presente ensaio busca encontrar, por intermédio da perspectiva dos Direitos Humanos, como uma linguagem e um signo comum, facilmente incorporável ao discurso cotidiano, pode redesignar o conceito de povo. A abordagem é crítica no tocante a uma análise essencialmente cosmopolita e demonstra as possibilidades interculturais de um conceito de povo para além do nacional, mas construída com a contribuição dos fenômenos e conflitos locais. A metodologia é analítica e exploratória, servindo-se de levantamento bibliográfico. $\mathrm{O}$ fato é que um canal de comunicação político e social deve ser estabelecido em favor do signo dos Direitos Humanos, possibilitando um reconhecimento cada vez mais amplo de sujeitos de direito, sendo esta construção o principal objetivo deste texto.

Palavras-Chave: Direitos Humanos; Nacionalidade; Povo Intercultural.

ABSTRACT: The modern elements that realizes the concept of State: people, territory and sovereignty, undergo a redefinition of the paradigmatic crisis observed in postmodernity. For example, the definition of people based on the national subject has become insufficient and we have started to observe intercultural possibilities for the establishment of a new concept of people. This essay seeks to find, through the perspective of Human Rights, as a common language and sign, easily incorporated into everyday discourse, it can re-designate the concept of people. The approach is critical

\footnotetext{
${ }^{1}$ Professor Associado do Departamento de Direito Público da Universidade Federal da Paraíba. Doutor em Teoria Dogmática do Direito pela Faculdade de Direito do Recife (UFPE). Mestre em Direito pela UFPB. Vice-líder do Grupo de Pesquisa em Prisões, Política Criminal e Criminologia (GPOC) com registro no DGP/CNPQ. Orientador de Mestrado e Doutorado na UFPB. E-Mail: gustavobm.batista@gmail.com ORCID: https://orcid.org/0000-0001-8196-5506.
} 
with regard to an essentially cosmopolitan analysis and demonstrates the intercultural possibilities of a concept of people beyond the national, but built with the contribution of local phenomena and conflicts. The methodology is analytical and exploratory, using a bibliographic survey. The fact is that a political and social communication channel must be established in favor of the sign of Human Rights, enabling an increasingly a broader recognition of subjects of law and the construction of this channel being the main objective of this text.

Keywords: Human rights; Nationality; Intercultural People.

Sumário: 1. Introdução. 2. Estado-Nação e a concepção de Povo como nacional: os princípios do processo civilizador europeu. 3. Dificuldades para o reconhecimento do outro dentro das concepções da modernidade: obstáculos para a diversidade. 4. Possibilidades interculturais de um conceito de povo: os direitos humanos como elemento de ligação. 5. Conclusão. 6. Referências.

\section{INTRODUÇÃO}

Os conceitos de povo, território e poder pensados como categorias analíticas do modelo de Estado Nação e Moderno foram os elementos de matriz europeia que mais se difundiram no Ocidente. O nacional como identidade de povo delimita uma origem étnica comum e forja um ideal de patrimônio cultural compartilhado pelos povos que habitam um determinado território há gerações. Consolidar a ideia do nacional foi indispensável para a delineação da Europa durante os séculos em que se alicerçou a concepção moderna de Estado Nação. Estipular fronteiras e diferenças, o eu e o outro, integrou o projeto de modernidade ocidental desde sua origem. A identidade nacional como categoria integrante de um Estado foi também estabelecida como um elemento de segurança ontológica necessário para a confiança da forma e das ações institucionais do Estado Moderno (GIDDENS, 1999, p. 48-51). O problema da nacionalidade e os conflitos inerentes ao longo processo pelo qual é tradicionalmente construída esta origem étnica comum acompanham, por exemplo, a própria História da Inglaterra desde o seu limiar (HUME, 2014, p. 27-33). As dificuldades de estabelecer uma "irmandade nacional" dentro de um território repleto de conflitos entre grupos com ideologias, práticas sociais e aspirações diferentes, foi o grande desafio da modernidade, encontrando, ainda hoje, dificuldades para se sustentar. 
Acrescenta-se ao conceito de povo o seu papel político, no exercício da cidadania e da participação democrática em processos de decisão. Aqui as dificuldades se aprofundam para o estabelecimento de uma "representação ampla", envolvendo igualmente não nacionais e os seus respectivos interesses. Ainda assim, este componente de "segurança" atribuído ao Estado pela limitação do conceito de povo, abre espaço para o não reconhecimento de direitos e práticas perversas, motivando a necessidade de construirmos um conceito amplo que permita o acesso à direitos por parte dos sujeitos ocupantes do território correspondente ao exercício de uma soberania estatal.

\section{ESTADO-NAÇÃO E A CONCEPÇÃO DE POVO COMO NACIONAL: OS PRINCÍPIOS DO PROCESSO CIVILIZADOR EUROPEU}

O fortalecimento desta identidade nacional se dá, originalmente, pelo compartilhamento de um instrumento de comunicação comum: a língua. Afinal, forjar uma nação somente seria possível por intermédio de um código comunicativo que permitisse o compartilhamento de ideias e tradições num determinado território de ocupação humana. Embora, muitas vezes, a formação deste código comunicativo resultasse numa perda da riqueza fonética e significante de vários dialetos populares que desapareciam dentro dos processos de centralização política, sendo unificados e simplificados dentro de uma gramática geral expressa em "normas cultas" para a utilização de um padrão linguístico único dentro de determinado território. Este processo forçado de engajamento e identificação marcou a construção do Estado Nação ainda em solo Europeu e foi transferido para as colônias europeias espalhadas pelo mundo. Tratase daquilo que se convencionou chamar por "processo civilizador", um processo de redução de contrastes e de padronização:

Nas áreas por onde se expandiu o ocidente, as funções sociais a que o indivíduo deve submeter-se estão mudando cada vez mais, de maneira a induzir o mesmo espírito de previsão e controle de emoções como no próprio Ocidente. Nesse caso, também, a transformação da existência social como um todo é a condição básica para civilizar-se a conduta. Por esse motivo, 
encontramos nas relações do Ocidente com outras partes do mundo os primórdios da redução de contrastes que é peculiar a todas as grandes ondas do movimento civilizador (ELIAS, 1993, p. 212).

Correlativamente, é um processo empobrecedor dos cotidianos humanos e suas variações, mas fundamentado na perspectiva da segurança pela ideia da formação de um forte vínculo de tradições entre os nacionais o que lhes permitiria unir-se contra identidades que colocassem em risco a sua forma de vida e organização social, emprestando-lhes uma maior segurança. Há muito influência do pensamento romântico na construção desta identidade nacional (RICUPERO, 2004), com apelos para tradições e comportamentos próprios de um povo, realçando sua singularidade e qualidades que o permitem unir-se contra o que lhes é oposto: o outro, não nacional, que lhe traz insegurança. Este processo simplifica a própria identidade humana e correlaciona uma estrutura de saber-poder e organização política voltada ao "estranhamento do outro" ou mesmo ao seu "não reconhecimento".

A própria expansão do modo de produção capitalista, o imperialismo europeu e a internacionalização da política e das formas jurídicas se tornaram elementos de instabilidade para a ideia original do Estado-nação e importaram na construção de "formas político e jurídicas" diversas para lidar, em especial, com regiões de forte diversidade etnográfica, ainda no próprio solo Europeu, como é o caso da Inglaterra, França e Alemanha. Entretanto:

Se já se podia colocar em dúvida a prudência de estender uma forma de governo que, mesmo nos países de antiga e estabelecida tradição nacional, não sabia como resolver os novos problemas da política mundial, era ainda mais duvidoso que ela pudesse ser transplantada para uma área onde sequer existiam as condições básicas para o surgimento de Estados-nações, ou seja, a homonogeneidade da população e a fixação ao solo [...] De fato, "basta um olhar ao mapa etnográfico da Europa para mostrar que o princípio do Estadonação não pode ser introduzido na Europa Oriental (ARENDT, 1989, p. 303).

Aparecem, assim, os Tratados de Minorias para dar conta de um contingente humano não identificado com as tradições nacionais: judeus, armênios, ciganos etc. Também aparecem, na Europa Oriental, as primeiras organizações políticas de Estado 
multi-étnicas, unidas por uma categoria ideológica de caráter supostamente universal: o islamismo, o socialismo etc. conseguiram produzir isso. No cenário internacional, as lutas ideológicas passam a ser travadas além das fronteiras estipuladas para um sujeito nacional, como o caso da Guerra Civil Espanhola, importando os primeiros elementos de constituição do exercício de uma "política mundial” (ARENDT, 1989, p. 300-336).

Tudo isso, desconstrói o formato do Estado Nação e põe em xeque instituições de proteção importantes fixadas para lidar com uma comunidade internacional formada a partir da ideia de Estados Nações, em virtude do surgimento destes fenômenos reativos ou inovadores, tais como: direito de asilo, política de refugiados e livre circulação de pessoas. Desta forma, a insegurança e o medo da diversidade se instalam no interior das comunidades nacionais forjadas no Ocidente, levando-os a uma renúncia e perda de direitos comumente aplicados com base na construção do Direito Internacional Público. A destruição do Estado-Nação aparenta também ser o fỉm dos Direitos do Homem, porque não se encontravam ainda internacionalmente estipulados até meados do século XX (ARENDT, 1989, p. 300). E, mesmo após a sua Declaração Universal, existe uma dependência prática da aderência e perfil institucional dos Estados singulares no sentido da efetivação dos Direitos Humanos.

Por sua vez, por exemplo, as várias tentativas sionistas de resolver o problema judaico demonstraram ao mundo que não é apenas o fato "de colocar solo aos pés de uma nação" que soluciona a vulnerabilidade de um povo diante da ausência de uma estrutura soberana que lhes oferte proteção. Cada dia mais, exige-se que alteremos o significado de "estranhos à comunidade nacional" e passemos a compartilhar desejos e sentimentos comuns aos vários sujeitos que conosco convivem num "espaço comunicativo" ampliado e não territorialmente tão definido como até então convivíamos. Precisamos desenvolver um novo vínculo de linguagem comum e universal que nos permita ampliar as formas de reconhecimento político, social e jurídico de pessoas como sujeitos integrantes de uma comunidade humana plurinacional e intercultural. Os Direitos Humanos podem oferecer várias saídas neste sentido. 


\section{DIFICULDADES PARA O RECONHECIMENTO DO OUTRO DENTRO DAS CONCEPÇÕES DA MODERNIDADE: OBSTÁCULOS PARA A DIVERSIDADE}

As categorias analíticas e cognitivas de identidade/semelhança/oposição/diferença estabelecem processos de classificação, controle, incorporação (assimilação) ou extermínio do outro. Enfim, o outro é um elemento de instabilidade e insegurança, tanto para o sistema comunicacional como para a organização política forjada a partir da identidade nacional, delimitada territorialmente. Esta concepção estática de povo a partir da ideia do nacional impede o fortalecimento de canais comunicativos de convergência ao mesmo tempo em que lança um olhar excludente sobre a divergência e a oposição da identidade. A classificação desta divergência cria fronteiras reais (não apenas imaginárias) que são vivenciadas por nacionais com relação aos estrangeiros. Para além dos territórios e fronteiras, constroem-se "muros invisíveis" que bloqueiam a comunicação humana e as possibilidades de convivência pacífica e emancipação social.

Todavia, a própria identidade social de um povo somente é monolítica enquanto uma ideia abstrata. Na prática, no interior de um determinado povo, as identidades são diversificadas por suas experiências de classe social, gênero, práticas religiosas e familiares. A sociedade é complexa e cheia de categorias humanas particulares que tornam a ideia abstrata de um nacional apenas um projeto de subjetividade mais abrangente com relação aos vários tipos humanos ocupantes de forma tradicional de um território delimitado.

Até mesmo as propostas estruturalistas e funcionais de análise, construídas a partir de uma identidade social monolítica e não reconhecedora das formas alternativas de organização social (vistas como desviantes, inovadoras ou rebeldes), existe uma classificação própria dos comportamentos, observando-se uma diferenciação entre eles a partir da atitude e ação diante da identidade social que é projetada, como no caso da clássica obra de Merton (2002, p. 210-239). Logo, o processo de uniformização da 
identidade é algo "mítico”, embora seja possível lançar estratégias no sentido de se obter um maior número possível de comportamentos sociais em conformidade com a identidade social projetada. O fato é que diante de uma identidade social projetada, podemos extrair diversos comportamentos humanos. Essa diversidade se enlarguece ainda mais quando percebemos a existência de várias "sociedades numa mesma sociedade" ou ainda quando estabelecemos canais cada vez mais cotidianos de contato entre uma sociedade nacional e sociedades estrangeiras como o ocorrido no atual contexto de "Globalização". Aparenta-se, com isto, romper qualquer segurança discursiva ou material diante da pluralidade de concepções que podemos extrair nestas zonas de contato extremamente tensionadas e superdimensionadas.

Há quem veja nessa diversidade um grave problema que ocasiona um elemento de instabilidade no interior do clássico modelo de Estado Nação. A questão não é assim tão simples, porque os processos de centralização política engendrados sobre esta ótica retiraram boa parte da autonomia subjetiva em nome do valor político e normativo de segurança nacional. Neste projeto, em princípio, a oposição não deveria estar posta no interior das sociedades nacionais, mas no ambiente externo, aquele habitado pela identidade estrangeira: “o estranho à comunidade nacional”. Afinal, para a segurança nacional, é difícil o enfrentamento de dois inimigos: um interno e outro externo. Depois, é mais fácil definir uma identidade estrangeira como inimiga, enquanto a divergência interna é tratada pelas estruturas comuns do controle social e da invisibilidade.

A diversidade, no contexto brasileiro, por exemplo, também já foi interpretada a partir de um modelo ideológico cultural de uma auto-percepção de uma comunidade única e especial (o povo brasileiro) formada pela combinação de três raças, como apresentada na hipótese interpretativa do Brasil formulada por Gilberto Freyre. Diante da dificuldade encontrada para estipular uma identidade nacional brasileira, coube ao sociólogo pernambucano lançar uma imagem peculiar sobre o Brasil e o brasileiro, como um povo formado por três raças em sua interpretação do Brasil. Seria um elemento importante para análise de um país onde se vive uma democracia racial e uma possibilidade para a classificação de uma natureza intercultural ao Brasil, não fosse o 
fato de que as instituições brasileiras, desde a Colônia, terem privilegiado uma matriz fortemente europeia e buscado invisibilizar as demais formas de organização social e política apresentadas pelas demais raças. Na realidade, o modelo de dominação colonial, persistente na cultura brasileira e motor da cultura escravocrata e de genocídio, sempre importou, no nosso caso, um não reconhecimento do outro, reproduzindo encobrimentos, silenciamentos e invisibilidades. A experiência brasileira teve suas particularidades, mas não deixou de apresentar problemas comuns ao restante da experiência colonial latino-americana, resultando numa grave exclusão social de diversas categorias humanas. A declaração da existência de uma diversidade racial formativa para o nacional brasileiro não modificou, substancialmente, as relações de poder e o espaço comunicativo no interior do país, marcado pela exclusão e violência racial. De qualquer maneira, a percepção de Freyre foi original e, ao menos, colocou no debate uma possibilidade nacional sem um vínculo originário e racial único, apesar das críticas de ocultação do racismo e da realidade opressiva da política colonial que tenha recebido com a sua interpretação do Brasil. Por isso:

Talvez se possa afirmar que Gilberto Freyre, mais do que qualquer outro autor, tenha contribuído para a formulação de uma ideologia que, como tal, ajuda a encobrir muito da violência que caracteriza a escravidão e continua a permear as relações raciais no Brasil. Por outro lado, e de maneira complementar, essa ideologia também auxiliou, como não seria possível antes, os brasileiros a elaborarem a imagem que gostam de ter de si mesmos (RICUPERO, 2008, p.99).

Os limites trazidos pelas categorias operadas por parte do pensamento moderno, autorizavam tão somente um reconhecimento da multiculturalidade, ainda que deixando invisíveis diversas facetas inerentes a este modelo de diversidade cultural, especialmente as relações de dominação e invisibilidade social das categorias raciais ou étnicas mais fragilizadas dentro do corpo social. O fato é que não é possível contar a "história do senhor" sem falar na "história do escravo" e, mesmo num contexto de opressão, há trocas e contribuições que permanecem. A culinária brasileira é riquíssima neste sentido, obtendo contribuições derivadas de um diálogo "gastronômico" entre as três raças, em especial, pela "Cultura do Açúcar” (FREYRE, 1997). 


\section{POSSIBILIDADES INTERCULTURAIS DE UM CONCEITO DE POVO: OS DIREITOS HUMANOS COMO ELEMENTO DE LIGAÇÃO}

A linguagem e a comunicação abrem possibilidades incríveis de convergência entre as pessoas e os grupos de pessoas, aproximando as tradições a partir das experiências humanas mais universais e comuns. Afinal, há nas tragédias e comédias humanas algo de universal e esta universalidade fica transcrita nas várias experiências comuns pelas quais passamos ao longo da vida. A própria finitude da vida é algo do qual universalmente não podemos fugir e nos permite aproximações discursivas importantes que nos oportunizam o reconhecimento do outro (GIDDENS, 1999, p. 97-105).

Tradições e culturas lidam com um espaço: o território em que se realizam. Também lidam com a organização da estrutura social, o exercício do poder e a classificação das pessoas dentro desta estrutura. Os códigos comunicacionais adquirem maior ou menor complexidade, dependendo do esforço a que os participantes da relação comunicativa sejam submetidos para lidarem com estas categorias de espaço, tempo e organização social, bem como com a resolução dos conflitos humanos que tais categorias ensejam. Entretanto, os sentidos estabelecidos nos códigos comunicacionais para lidarem com estas categorias permitem variações significativas importantes que se transmitem pelo esforço comunicativo. Quanto maior e mais ampliado for o esforço, melhor será a habilidade de compartilhar sentido(s) por parte do código comunicativo e dele ser incorporado a um cotidiano ou a um projeto existencial. Neste ponto, a própria divergência sugere um esforço comunicacional ou, simplesmente, o silêncio. A ação com sentido promove uma constante mobilidade das categorias analíticas identidade/divergência, proporcionando afastamentos e aproximações que determinam aquisições de ideias, conceitos e instrumentos relacionais pelo e a partir do esforço comunicativo. Este esforço permite o enriquecimento dos códigos de linguagem e a aquisição de novas atitudes para lidar com os conflitos humanos, bem como a proposição de outros projetos de identidade, inclusive, sobre quem é o povo? 
A habilidade comunicativa permite numa maior habilidade para resolver conflitos e aproximar projetos éticos e existenciais. Desta forma, o esforço comunicativo imposto pelo simples fato de existir a divergência é um elemento enriquecedor, prejudicando o desenvolvimento da habilidade humana em lidar com os conflitos apenas quando convertido em estratégia de poder e submissão do outro. Por isso, na essência, como seres comunicativos, somos e estamos para além da delimitação de um nacional, porque compartilhamos a experiência humana comum da comunicação e podemos, a partir dela, expandir as formas de organização do poder social a fim de que reconheça, cada vez mais, outras experiências humanas e outros projetos de identidade.

Uma concepção intercultural de povo dimensiona, propriamente, as possibilidades de um desenvolvimento comunicativo do que é humano. Certamente, há de se ter cuidado nesta concepção no tocante ao não cancelamento da diversidade, porque o que se produz posteriormente não se pode conceituar como interculturalidade. Somente existe interculturalidade em virtude da divergência e da complexidade das formas de existência humana e social. Assim sendo, esta dimensão deve se apropriar daquilo que é colocado no debate entre pensadores cosmopolitistas e anticosmopolitistas e dar um salto, indo além.

O projeto cosmopolita moderno não pode ser aceito como intercultural, uma vez que propõe uma unificação da identidade humana em torno, quase que exclusivamente, da experiência humana ocidental, cancelando as identidades locais e orientais. Ele se insere na ideia de ocidentalidade (não universalidade, propriamente) e é um projeto auspicioso para grandes empreendimentos econômicos, propondo um mundo parcialmente sem fronteiras, cuja unificação é alcançada com base na forma jurídica ocidental e na justificação internacional de uma "comunidade internacional": o direito como artífice da paz (MANNONI, 2006, p. 585).

Neste cenário, as fronteiras determinariam a exclusão das identidades locais que resistem à ocidentalização civilizatória pela forma jurídica, tornando-se o muro que protege a cidadania cosmopolita da barbárie. No cosmopolitismo ocidental, não cabe, por exemplo, a pobreza, apenas a prosperidade e não se encaixam as identidades que 
contrariam a razão instrumental posta em marcha desde o projeto de modernidade. Sua forma jurídica e sua justificação filosófica alcançam tão somente, de maneira parcial, os vários fenômenos locais que importam numa efetiva divergência desta proposta de globalização ocidental. Todavia, as suas intenções devem ser colocadas sobre suspeita, sendo muito bem vinda a crítica dos pensadores anti-cosmopolitistas que delimitam as categorias analíticas que determinam e orientam o cosmopolitismo ocidental e suas consequências, especialmente quanto à globalização da forma jurídica ocidental e de suas instituições (Tribunais Regionais e Internacionais, Parlamentos Regionais e Internacionais etc.). Desta forma:

Seria um error infravalorar la importancia que la doctrina occidental del <<globalismo jurídico >> ha tenido em la ultima década del siglo XX, tras la caída del Imperio Soviético y el final del bipolarismo. Su relevância internacional tiene que ver seguramente con la hegemonia económico-militar que parecen demandar la unificación a escala planetária también de las estructuras normativas e jurisdiccionales. Pero además, tiene que ver com la circunstancia de que se trata de una filosofia del derecho orientada a legitimar las instituciones internacionales hoy existentes y, de manera particular, sus más recientes desarollos <<humanitários〉> y judiciales (ZOLO, 2005, p. 121).

O mundo cosmopolita ocidental dar continuidade ao processo civilizador principiado na modernidade, estipulando no cenário internacional as mesmas instituições que já sabemos os limites e dificuldades para lidar com os conflitos no espaço interno dos Estados. Daí o motivo pelo qual o pensamento anti-cosmopolita denuncia as suas contradições e percebe sua natureza seletiva e excludente.

O anti-cosmopolitismo denuncia estas pretensões de poder e ocidentalização presentes no pensamento cosmopolita hegemônico. Demonstra, muitas vezes, o sentido único e centralizador político e econômico, favorável ao modelo capitalista triunfante, na forma jurídica tomada pelo cosmopolitismo ocidental que enquanto autoriza para poucos ultrapassar as fronteiras nacionais, deixou à margem dos seus benefícios uma grande parcela de pessoas humanas cujos projetos existenciais não se identificam com aqueles da globalização ou cuja realidade de vida não permite acessar quaisquer benefícios originados a partir dela. Certamente, este processo é uniformizador o 
suficiente para não ser classificado como "intercultural”, ainda que, superficialmente, produza aproximações. Todavia, não se trata de uma "internacionalização de direitos", por mais que propicie estratégias neste sentido, mas, na prática, de uma “internacionalização do capital”. Portanto:

Em nenhum âmbito da atividade humana, a internacionalização é assim tão completa como no âmbito financeiro", escrevia em 1909 Norman Angell no felicíssimo The Great Illusion, manifesto pacifista de toda uma geração. Precisamente como tinha profetizado Kant, o mundo era atravessado pelos mil fios do capital e do comércio que não conheciam fronteiras e não tiravam nenhuma vantagem das guerras. Eis, em síntese, a estratégia: "atingir uma organização social construída sobre bases diversas daquelas territoriais e nacionais (MANNONI, 2006, p. 594).

As categorias críticas trazidas a partir do pensamento anti-cosmopolita são exatamente aquelas que nos servem para discutir possibilidades de um modelo cosmopolita contra-hegemônico. Este, somente é possível, tentando ultrapassar e resistir à forma comum do cosmopolitismo ocidental. Portanto, torna-se possível se servindo das categorias críticas de análise anti-cosmopolitas, embora também percebendo nelas alguns limites para uma proposta genuinamente intercultural. Há uma parcela conservadora de resistência anti-cosmopolita que vislumbra a manutenção de um status quo contrário à igualdade entre pessoas e aos Direitos Humanos.

Se, por um lado, as tradições e localismos criam identidades importantes que se opõem ao cosmopolitismo ocidental hegemônico dentro de sua "forma jurídica", por outro lado podem servir de obstáculo fundamentalista ao enriquecimento da comunicação humana e, portanto, se opor às análises inerentes a uma ideia de interculturalidade. Certamente, o impasse demanda um esforço que não pretendemos esgotar neste artigo, mas podemos indicar possibilidades para encontrar saídas. Uma delas seria buscar um não reducionismo às formas jurídicas para lidar com os conflitos humanos, precisamos fugir do modelo convencional utilizado a partir da modernidade em buscar a paz tão somente pelo direito. Também este modelo tornou-se um elemento que empobrece a linguagem e não permite que ela assuma outras dimensões. Todavia, daí, surge outro problema: como impor um limite ético aos discursos fora do controle 
normativo-jurídico? Como evitar que as soluções prestadas ao conflito não sejam aquelas comuns ao estado de barbárie? Reconhecendo os limites da forma jurídica, podemos tentar desenvolver estratégias mais amplas, que não dispensem completamente o auxílio do mínimo ético estipulado pelo direito, mas permita um sistema comunicativo mais amplo, aperfeiçoando a linguagem para lidar com os conflitos. Desta forma, precisamos encontrar nos movimentos insurgentes e de resistência ao processo civilizador ocidental, elementos que nos permitam aproximações (SANTOS, 2013, p. 27). Vejam que alguns destes movimentos insurgentes, propõe, inclusive, um reposicionamento da religião na vida política (insurgência islâmica), cujo potencial não podemos compreender dentro dos limites emprestados pela modernidade ocidental, daí:

Ao pensamento convencional dos direitos humanos faltam instrumentos teóricos e analíticos que lhe permitam posicionar-se com alguma credibilidade em relação a esses movimentos, e, pior ainda, não considera prioritário fazêlo. Tende a aplicar genericamente a mesma receita abstrata dos direitos humanos, esperando, dessa forma, que a natureza das ideologias alternativas e universos simbólicos sejam reduzidos a especificidades locais sem nenhum impacto no cânone universal dos direitos humanos (SANTOS, 2013, p. 27).

O problema é que os discursos de aproximação se tornam cada vez mais distantes se tentamos reduzir, por exemplo, movimentos de matriz fortemente teológica, à forma jurídica emprestada aos direitos humanos em sua dimensão ocidental. Quando, na realidade, o que deveríamos fazer para produzir uma comunicação válida a fim de se obter a resolução do conflito nesta espécie, na realidade, seria tentar uma aproximação com matrizes teológicas de cunho progressista, estimulando suas práticas. Logo, ao invés de simplificar a linguagem e os conflitos, como sempre foi feito pelo modelo reducionista da modernidade, tornar este campo comunicacional mais aberto e complexo, realçando a existência de práticas religiosas progressistas que respeitam a dignidade da pessoa humana e estendendo, por intermédio delas, o alcance conceitual que é dado pela forma tradicional da religião.

E, sobre o ponto de vista da religião, por exemplo, o problema suplanta a ideia de identidade nacional, tornando-se, num determinado prisma, um modulador universal, 
uma vez que as religiões converteram vários povos, permitindo um elemento de ligação comum entre todos eles. Por isso, quando o movimento insurgente possui uma matriz religiosa, esta dinâmica comum a partir do fundamento religioso possibilita servir-se das categorias universais da própria religião como um canal intercultural para a resolução do conflito. Também nos permite apoiar práticas progressistas (não tradicionais) destas matrizes religiosas, assegurando uma aproximação discursiva bastante proveitosa entre a forma jurídica dos direitos humanos e as práticas religiosas, o que seria impossível dentro de uma visão convencional e hegemônica de direitos humanos. Modificar os “tópicos utilizados nas zonas de contato" pode ser um valioso instrumento de ação intercultural, evitando-se que rivalidades se acirrem onde deveria existir aproximação das experiências, por isso, nada melhor de que se utilizar da própria religião para lançar projetos éticos comuns quando o conflito tem uma base religiosa de análise. Aprofundar o conhecimento acerca das suas próprias tradições, coloca-las a prova, desenvolvendo práticas e atitudes a partir dos valores calcados nelas é um instrumento de interculturalidade. Precisamos, também, estar abertos para ampliar os códigos comunicacionais, servindo-se, as vezes, das mesmas categorias universais que lidam com um determinado fenômeno social, sobre os problemas que se apresentam naquele aspecto da estrutura social, até mesmo aqueles de matriz religiosa, porque o fato se resume na maneira com a qual desenvolvemos a comunicação humana: se ela se der na forma convencional, há grande chance de não lograr êxito, porque não conseguirá comunicar o sentido pretendido. Uma última vez, no tocante ao problema da religião e sua potencialidade intercultural, temos que:

À luz dos desafios colocados pelas teologias políticas, a reinvenção dos direitos humanos e a sua transformação num instrumento de emancipação social em diferentes contextos culturais exige um exercício de tradução intercultural (Santos, 2004; 2006a, p. 122-66) e hermenêutica diatópica (Panikkar, 1979; Santos, 1995, p. 273-78; 2006b, p. 433-70) através do qual as limitações recíprocas de concepções alternativas de dignidade humana possam ser identificadas, abrindo assim a possibilidade de novas relações e diálogos entre elas. A isto chamo ecologia de saberes (Santos, 2006b, p. 13766; e 2009b, p. 31-83), um exercício epistemológico baseado na incompletude de qualquer tipo de conhecimento humano e destinado a identificar conhecimentos distintos e critérios de rigor e validade que operam 
credivelmente nas práticas sociais de modo a desenvolver interações criativas entre eles (SANTOS, 2013, p. 100-101).

De qualquer forma, é preciso estimular um modelo de autoconhecimento que promova uma ruptura com formas tradicionais conservadoras e fundamentalistas sem que, para isto, ocorra uma completa perda das tradições e da complexidade linguística envolvida nelas. A auto-reflexão nos leva a compartilhar experiências de forma mais abrangente e questionar as tradições que limitem a autonomia humana e as possibilidades de comunicação. Um pensamento cosmopolita contra-hegemônico não pode cancelar o local e o local não pode impedir, por completo, a ideia de universalidade.

O debate aprofunda-se neste ponto, porque não é bastante o reconhecimento da diversidade, podemos estipular, inclusive, a perspectiva da multiculturalidade dentro da "forma jurídica" e isto já foi feito por diversas Constituições contemporâneas. Todavia, o que se põe aqui é a própria essência significante de um povo intercultural, apto a estabelecer comunicações dotadas de sentido universal, embora sem perder sua origem e sua história. Para isto, não é bastante proteger legalmente o multiculturalismo como uma espécie de patrimônio espiritual de um povo e, mesmo, da comunidade internacional, porque ele somente identifica a diversidade presente no mundo e na sociedade. O que necessitamos é do estabelecimento de canais comunicativos a partir da própria experiência humana que possibilitem um novo campo de experiências comunicativas dentro de um significado próprio de interculturalidade que é conviver na diversidade e não apenas declarar a presença da diversidade.

Apostar na liberdade e na autonomia individual e no enriquecimento da linguagem, pela incorporação de conceitos e categorias de análise novas, podem, neste contexto, exprimir um primeiro elemento no sentido da possibilidade de assegurar uma convivência mais ampla entre as pessoas, reconhecendo-se a diversidade das formas coletivas de existência. Assim:

Um pluralismo de modos de ler tradições ambivalentes sempre fornece a ocasião para discussões de auto-entendimento, que esclarecem os partidos litigantes sobre a necessidade de decidir conscientemente sobre o modo de 
vida que desejam assumir, sobre as tradições que pretendem continuar ou romper (HABERMAS, 2003, p. 131).

A interculturalidade deve possuir um conteúdo reflexivo e crítico no tocante às tradições, não dispensando a possibilidade de construir categorias universais a partir delas. Assegurar o que foi conquistado pelas formas tradicionais de vida e lhes permitir desenvolver projetos de existência adaptados à contemporaneidade (presentificar as tradições) é plenificar a autonomia e a autodeterminação humana e de um povo. Neste ponto, os direitos humanos (ao lado de outras categorias universais) são instrumentos relevantes para assegurar a instalação deste "campo comunicacional” mais amplo e apto para lidar com os conflitos de forma a produzir eco sobre os vários projetos de sociedade e de autodeterminação lançados no mundo contemporâneo, sem perder de vista aquilo que corresponde à história e à tradição de um povo. Os direitos humanos, especialmente quando refletidos de forma não convencional, propõem uma deslegitimação das formas político e jurídico modernas, criando espaços para se repor a legitimidade de um código comunicativo que permita a interculturalidade. E, mesmo sobre um paradigma convencional dos direitos humanos, podemos afirmar que:

Os direitos humanos e o princípio da soberania do povo formam as ideias em cuja luz ainda é possível justificar o direito moderno; e isso não é mera causalidade. Pois a essas ideias vêm somar-se os conteúdos que sobrevivem, de certa forma, depois que a substância normativa de um ethos ancorado em tradições metafísicas e religiosas passa pelo crivo de fundamentações póstradicionais (HABERMAS, 2003, p. 133).

Como a letra do Samba campeão da Mangueira de 2019, sobre o Brasil e uma história em há mais invasão de que descobrimento, é necessário aqui descortinar a ideia de que somos estrangeiros provenientes de várias partes do mundo que destruíram civilizações locais e construíram o seu próprio mundo e sociedade. O fato é que já surgirmos plurinacionais, restando apenas estabelecer um vínculo que perpasse toda a experiência comum e humana que nos define. O que são os Direitos Humanos senão um bálsamo para uma experiência comum de sofrimento? O sofrimento que nos define como humanos é o mesmo que nos propicia a crítica das instituições que sustentam políticas de exclusão e não reconhecimento. Não há outra razão tão universal e 
existencial como o fato de sofrer e não há motivo mais sublime para legitimar a ação humana de que a busca incessante da redução deste sofrimento. Sofre-se pela infância abandonada e desprotegida, pela escravidão ou desemprego, pela falta de cuidados na velhice, pelo desamparo da saúde e tudo isso reclama uma linguagem balsâmica comum a partir dos Direitos Humanos. A fraqueza que vincula a humanidade é igualmente a nossa força comum e reflexiva, o espelho que nos permite a crítica e o retorno da razão e nos identifica de maneira aberta e plural. E quantas invasões ainda serão necessárias para descobrirmos que esta identidade não precisa ser nacional? O signo religioso já produziu algumas experiências que permitem a reunião de várias nações, comprovando que é possível compartilhar valores em diversas etnias distintas. Seria, possível, então, fazer o mesmo a partir dos Direitos Humanos? Por que esta linguagem ainda não conseguiu superar as barreiras que, no passado, impulsionaram a construção de formas universais sobre signos religiosos cristãos ou islâmicos? Qual o aprendizado histórico de choques culturais e invasões que nos permitem construir estruturas de reconhecimento não excludentes, não genocidas e não silenciadoras do outro?

Dificilmente uma ideia intercultural de povo atualmente consegue se sustentar sem a declaração universal e as práticas de direitos humanos. Afinal, o espaço comunicativo propiciado a partir da consolidação democrática e positivada normativamente dos direitos humanos e de seu ativismo político é o que permite um canal de interculturalidade. Todavia, a sua "forma convencional" ocidentalizada é insuficiente para dar conta da diversidade humana existente, o que determina não apenas a necessidade de "traduções culturais", mas de ampliação completa do espaço comunicativo humano para lidar com "zonas de contato" cada vez mais complexas, coisa que não é mais possível se extrair da experiência "civilizatória ocidental": precisamos, no campo da comunicação, de menos atualização histórica e mais aceleração evolutiva dos modelos, na forma como foi pronunciada por Ribeiro (2007).

\section{CONCLUSÃO}


A concepção intercultural de povo exige uma formação cultural e humana consciente da diversidade e com habilidade para efetivar uma tradução cultural. Certamente, não corresponde ao modelo hegemônico de identidade popular (nacional ou cidadã) proposto pela ocidentalização das categorias políticas e das formas jurídicas posto em marcha a partir do "processo civilizador" de matriz europeia. Afinal, não se trata de uma ideia centrada na "mera atualização histórica" com formas civilizadas de organização social e política provenientes dos "países centrais". Todavia, é uma proposta alicerçada na superação de uma forma de identidade monista, estipulando possibilidades criativas e transculturais de se expressar e se identificar como povo e popular. Daí a necessidade da tradução cultural como um primeiro elemento de abertura à diversidade cultural e sua aceitação. As vezes, isto já ocorre naturalmente e sem ser percebido, o que indica a necessidade apenas de realçar as situações onde a "tradução cultural" foi assim produzida, para argumentar a sua possibilidade de realização em outros fatos ou conflitos humanos, estendendo os conceitos linguísticos aptos a lidarem com um determinado problema de reconhecimento e inclusão social. O povo se torna tradutor cultural pela experiência comum da comunicação e, portanto, está vinculado por ela. As "atividades comerciais" e de troca, por exemplo, são um ambiente comunicativo que amplia esta possibilidade da abertura de canais de representação e participação institucional independente da nacionalidade. Vale lembrar que, a partir das práticas mercantis e comerciais, um "direito das gentes" (GILISSEN, 2001, p. 96) se constituiu na Roma antiga para abrigar relações, demandas e formas jurídicas dos povos conquistados, oportunizando-os um canal de comunicação com as instituições políticas e decisórias do Império (ALVES, 1990, p. 84-85). Esta experiência, a partir das relações comerciais e humanas desenvolvidas no Império Romano, possibilitou alargar, por intermédio de um direito comum, o acesso de sujeitos de nacionalidades diferentes à jurisdição dos Pretores romanos. A antiguidade clássica conheceu assim uma civilização que, mesmo com restrições, estendeu o conceito de cidadania para além da ideia de um nacional como acabou estabelecido pelo Édito de Caracala (GILISSEN, 2001, p. 94). Certamente, tratou-se de um cosmopolitismo hegemônico e interessado, mas, 
igualmente, propiciador de uma experiência institucional enriquecedora para os princípios e noções de equidade e obrigações alcançados pelo Direito Comum que foram transculturados para diversos povos e incorporados ao seu cotidiano, em especial, na Europa Ocidental e cristã.

Por sua vez, a concepção intercultural de povo, da mesma maneira que valoriza e vincula as identidades a suas tradições, realçando as origens e diversidade, estipula categorias universais aptas a lidarem com a pluralidade de identidades, reconhecendoas como uma riqueza humana, jamais como um objeto de estranhamento, instabilidade e insegurança contra os quais devemos proteger uma "comunidade nacional". Estas categorias universais podem ter matriz ideológica, religiosa ou mesmo origem em formas não convencionais e não reducionistas de organização política e da prática do direito, compartilhadas pela experiência da comunicação humana. $\mathrm{O}$ importante é que o povo se reconheça pela experiência daquilo que é humano e aquilo que é humano não lhe seja estranho (Publius Terentius Afer, 195 a.C.). E, como dito, nada é mais humano que o sofrimento e a busca de conforto diante das dores e abandono da humanidade.

As relações humanas e culturais se desenvolvem no espaço "ecológico" da comunicação onde os saberes humanos competem ou cooperam, rompendo, devorando ou mantendo tradições. Este espaço "ecológico" deve ser preservado como "espaço comunicativo", estabelecendo-se a linguagem e a comunicação como a máxima expressão do povo e como o seu elemento vinculante. $\mathrm{O}$ intercultural somente se torna viável por meio da comunicação e a forma máxima de expressão popular é o signo que se pode inserir no contexto de uma ação que comunica, recebendo sentido e sendo dialogicamente questionado. Logo, reconhecemos como povo e popular tudo o que integra a experiência de comunicação humana. E os direitos humanos como signo e expressão maior desta experiência.

Assim sendo, uma concepção intercultural de povo vincula todos a partir da própria experiência humana da comunicação e é ela que nos dá um conceito apto a respeitar a diversidade cultural existente. É a comunicação que nos fornece a habilidade de traduzir culturas diferentes e de ser e continuar sendo povo no desenvolvimento e 
incorporação dos saberes produzidos popularmente. Um povo para além do nacional; um povo universal sem perder as várias identidades que o compõem e suas tradições locais que lhe permitem uma experiência cultural peculiar. O grande desafio será definir as formas de participação política junto ao Estado deste "povo intercultural", estabelecendo o acesso a direitos e possibilidades de representação dos seus interesses.

\section{REFERÊNCIAS}

ALVES, José Carlos Moreira. Direito Romano, v. 1. Rio de Janeiro: Forense, 1990.

ARENDT, Hannah. Origens do Totalitarismo: anti-semitismo, imperialismo e totalitarismo. Trad. Roberto Raposo. São Paulo: Companhia das Letras, 1989.

ELIAS, Norbert. O processo civilizador. Trad. Ruy Jungmann. Rio de Janeiro: Jorge Zahar Editor, 1993.

FREYRE, Gilberto. Açúcar: uma sociologia do doce com receitas de bolos e doces do Nordeste do Brasil. 23 ed. Rio de Janeiro: Companhia das Letras, 1997.

GIDDENS, Anthony. Identità e Società Moderna. Napoli: Ipermedium Libri, 1999.

GILISSEN, John. Introdução Histórica ao Direito. Trad. A. M. Hespanha e L. M. Macaísta Malheiros. 3. ed. Lisboa: Fundação Calouste Gulbenkian, 2001.

HABERMAS, Jürgen. Direito e Democracia: entre facticidade e validade, v. 1. Trad. Flávio Beno Siebeneichler. Rio de Janeiro: Tempo Brasileiro, 2003.

HUME, David. História da Inglaterra: da invasão de Júlio César à Revolução de 1688. Trad. Pedro Paulo Pimenta. 2. ed. São Paulo: Editora UNESP, 2017.

MANNONI, Stefano. Estado Nacional de Direito e direito internacional. In: COSTA, Pietro; ZOLO, Danilo (Orgs.). Estado de Direito: história, teoria e crítica. Trad. Carlo Alberto Dastoli. São Paulo: Martins Fontes, 2006.

MERTON, Robert K. Teoría y Estructura Sociales. Trad. Florentino M. Torner e Rufina Borques. 4. ed. Ciudad del Mexico: Fondo de Cultura Economica, 2002.

RIBEIRO, Darcy. As Américas e a Civilização: processo de formação e causas do desenvolvimento desigual dos povos americanos. São Paulo: Companhia das Letras, 2007. 
RICUPERO, Bernardo. O romantismo e a ideia de nação no Brasil. São Paulo: Martins Fontes, 2004.

RICUPERO, Bernardo. Sete Lições sobre as interpretações do Brasil. São Paulo: Alameda, 2008.

SANTOS, Boaventura de Sousa. Se Deus fosse um ativista dos Direitos Humanos. São Paulo: Cortez, 2013.

ZOLO, Danilo. Los Señores de la Paz: una crítica del globalismo jurídico. Trad. Roger Campione. Madrid: Editorial Dykinson, 2005.

Data da submissão: 02/02/2020

Data da primeira avaliação: 30/04/2020

Data da segunda avaliação: 06/05/2020

Data da aprovação: 06/05/2020 